\title{
SUSTENTABILIDADE CORPORATIVA ATIVO INTANGÍVEL E GERAÇÃO DE VALOR DE LONGO PRAZO
}

Fabiana Costa ${ }^{1}$

\section{RESUMO}

Este artigo tem por objetivo promover uma reflexão em relação a evolução do conceito de sustentabilidade e as suas implicações no setor privado, nos dias atuais. Apoiado na necessidade da promoção de um desenvolvimento sustentável pelo setor, onde o lucro não pode ser mais a única preocupação, sendo essencial um novo posicionamento, além da preocupação com as questôes sociais, ambientais e econômicas, por demanda dos stakeholders (sociedade, investidores, entre outros).

A sustentabilidade passa a ser essencial para geração de valor de longo prazo das empresas.

Palavras chave: Sustentabilidade; Desenvolvimento sustentável; Setor privado.

\section{ABSTRACT}

This article aims to promote a reflection on the evolution of the sustainability concept and its implications in the private sector, nowadays. Supported by the need to promote sustainable development

1 Mestranda do Programa de Pós-graduação em Economia Política da Pontifícia Universidade Católica de São Paulo. 
-• Economia Brasileira em Debate

for the sector, where profit cannot longer be a single concern, a new positioning is essential, as well as the concern with social, environmental and economic issues, as demanded by stakeholders (society, investors, Among others). Sustainability becomes vital and essential for generating long-term value for companies.

Key words: Sustainability; Sustainable development; Private sector.

\section{INTRODUÇÃO}

É possível um capitalismo capaz de levar o mundo em conta?

ABRAMOVAY, 2012, p. 129.

As empresas podem ser sustentáveis? É possível que as empresas tenham outros objetivos além dos lucros? O que a sociedade e os investidores entendem por sustentabilidade e esperam das empresas?

Nos dias atuais, nos deparamos com a necessidade de repensar o modelo de atuação do setor privado, onde o único objetivo é a geração de lucro e o sucesso máximo no curto prazo. É necessário reforçar a preocupação com a sustentabilidade, com a promoção do desenvolvimento sustentável, conceituado pela Organização das Nações Unidas (ONU) por aquele capaz de satisfazer as necessidades do presente sem comprometer a possibilidade das gerações futuras de satisfazerem suas próprias necessidades.

Fato é, que até um período recente, este conceito era ausente nas estratégias de negócios. O que era considerado um paradoxo, uma vez que é impossível se projetar no futuro, ignorando as questões relacionadas a promoção do desenvolvimento sustentável. É essencial a preocupação com as questões sociais, econômicas e ambientais.

A transição para uma economia capaz de promover desenvolvimento sustentável é uma tendência da economia mundial. Repensar o sistema, a forma de fazer negócios e os impactos socioambientais possui caráter prioritário. A busca pelo desenvolvimento sustentável precisa ser estratégica, inerente aos negócios e a atuação do setor privado.

O conceito de sustentabilidade evoluiu nas grandes corporaçôes e em agendas estratégicas de âmbito mundial. As áreas de sustentabilidade corporativa estão ganhando espaço nas agendas dos CEOs. A Sustentabilidade começa a ser um critério de análise para investidores, as bolsas de valores em âmbito mundial, não só acompanham a performance financeira, mas a performance sustentável das empresas. 
O conceito evoluiu nos últimos anos, da mesma forma que os desafios também evoluíram. Fato é que, o conceito não pode ser apenas ilustrado nos relatórios empresariais ou tratado como Green washing (marketing verde).

O mainstreaming da sustentabilidade no setor privado está assustando as empresas, as demandas são urgentes e rever a forma de fazer negócios tem se tornado vital.

Este artigo busca ilustrar a evolução do conceito de sustentabilidade nos últimos anos, reforçando os desafios e as demandas atuais.

$\mathrm{O}$ artigo foi dividido em 5 itens, contemplando essa introdução e uma conclusão.

A ideia central é demonstrar a evolução do conceito de sustentabilidade e a necessidade das empresas em gerar valor de longo prazo, contribuindo com a promoção do desenvolvimento sustentável. Através da pressão da sociedade e do monitoramento do conceito, por relevantes indicadores de sustentabilidade.

\section{SUSTENTABILIDADE: CONCEITO}

A palavra Sustentabilidade, vem de "sustentável" provém do latim sustentare. Indica uma característica ou condição de um processo e/ou sistema que permite a sua permanência, em certo nível, por um determinado prazo2.

O termo sustentabilidade é comum nos dias atuais, principalmente nos mais diferentes ambientes corporativos. Porém, o conceito começou a ser traçado, em 1987, no Relatório Brundtland ${ }^{3}$, a Organização das Nações Unidas (ONU) classificou o conceito de sustentabilidade ou "desenvolvimento sustentável" como sendo aquele que "satisfaz as necessidades do presente sem comprometer a possibilidade das geraçôes futuras de satisfazerem suas próprias necessidades”(WORLD COMMISSION..., 1987).

O conceito de necessidades, também surge a partir de 1970, trazendo novas exigências e reflexões relacionadas ao conceito de pobreza. Inserindo, condições essenciais como o acesso a água potável, saneamento básico, saúde, educação e cultura. Esse conceito passou a ser adotada pelos órgãos internacionais, principalmente por aqueles que integram a Organização das Nações Unidas (ONU), representando uma ampliação ao conceito de sobrevivência.

2 “Sustentabilidade". https://pt.wikipedia.org/wiki/Sustentabilidade.

3 Relatório de Brundtland - Documento final da Comissão sobre Meio Ambiente e Desenvolvimento cujo lema era: uma agenda global para a mudança, criado após a Primeira Conferência Mundial sobre o Homem e o Meio Ambiente em Estocolmo. Recebeu esse nome em homenagem à primeira ministra da Noruega, GroHarlemBrundtland, que liderou os trabalhos. 
Em 1980, ampliando o conceito de necessidades, surge o conceito de privação, definindo que sair da linha de pobreza significava ter alimentação, conforto, desenvolvimento, comportamento de papéis e comportamento socialmente adequados. Tese que ficou conhecida como "Consenso de Washington" 4.

O conceito de privação relativa evoluiu tendo como um de seus principais formuladores o indiano Amartya Sen, ganhador do prêmio "Nobel" de economia em 1999.

Segundo Amartya Sen (2000), a pobreza pode ser definida como uma privação de capacidades básicas de um indivíduo e não apenas como uma renda inferior a um patamar pré-estabelecido. Seu conceito introduz variáveis mais amplas, chamando a atenção para o fato das pessoas sofrerem diversos tipos de privações e em várias esferas da vida. Ser pobre não implica somente privação material. Podendo refletir em: morte prematura, subnutrição, morbidez, analfabetismo, deficiências, recursos naturais, baixa renda, entre outros.

Dessa forma, o conceito traçado pela ONU nos anos 70, foi potencializado. Incorporando questôes de caráter social, ambiental e econômico. Necessidades, não estão apenas associadas a privação de renda.

De acordo com Sen,

Vivemos um mundo de opulências sem precedentes, mas também de privação e opressão extraordinárias. O desenvolvimento consiste na eliminação de privações de liberdade que limitam as escolhas e as oportunidades das pessoas de exercer ponderadamente sua condição de cidadão (Amartya Sen, 2000).

Podemos dizer que Sen, expõe uma nova possibilidade, rumo a concepção de sustentabilidade à humanidade. Preferentemente a pensar, a questão do desenvolvimento como o aumento do desempenho econômico, é necessário pensar, antes, nas oportunidades e qualidade de vida às pessoas, para desenvolverem adequadamente suas capacidades além do ponto de vista econômico e da renda.

Trata-se de um grande erro da lógica econômica neoliberal: ainda que não seja possível uma sociedade que somente preze pelos interesses individuais, tampouco se aceitaria que os interesses individuais se sobrepusessem às necessidades coletivas. (SEN, 1999, p. 32)

4 Consenso de Washington - formulado em novembro de 1989 por economistas de instituições financeiras situadas em Washington, trata-se de uma conjunção de grandes medidas que se compõem de regras básicas, para promover o ajustamento macroeconômico dos países em desenvolvimento que passavam por dificuldades. 
O egoísmo universal como uma realidade pode muito bem ser falso, mas o egoísmo universal como um requisito da racionalidade é patentemente um absurdo (ibidem, ibidem). Dessa forma, as saídas apontadas, contra o ideal individualista levantado, terão reações diretas nas questôes sociais e ambientais.

Nesse sentido, uma saída deveria ser o fundamento na ética, responsável por reger as escolhas humanas e as questões logísticas. A dimensão ética deveria determinar como as necessidades/utilidades humanas deveriam ser satisfeitas. Outra saída apontada é a econômica, que deveria ser aquela pautada na logística sustentável das coisas, considerando-se a ordem humanitária pela qual se deve valorizar as atividades econômicas (SEN, 1999, p. 20).

Sem destaca, as saídas para a sustentabilidade na teoria econômica. Não sendo possível isolar o os aspectos éticos, perante o risco de ficar no reducionismo da noção utilitarista e de interesse próprio das relações humanas, focando no lucro máximo capitalista e, desconsiderando a prioridade das questôes socioambientais, essenciais para o desenvolvimento econômico.

Dessa forma, em relação ao conceito de sustentabilidade, Sen traçou caminhos alternativos, de forma mais coerente em relação às reais necessidades humanas e sua consequente relação com o meio. Destacando a tentativa de resgate da importância da condição humana na realidade econômica.

Diante da realidade atual, os desafios são muitos, mas, mostra-se necessário a busca por minimizar os impactos já causados e a demanda por um novo modelo de desenvolvimento, um desenvolvimento sustentável.

\section{SUSTENTABILIDADE CORPORATIVA}

Diante da explicação e da evolução do conceito de sustentabilidade já apresentado, é importante reforçarmos o papel do setor privado à promoção do desenvolvimento sustentável. Nesse artigo, definimos sustentabilidade corporativa como a incorporação de aspectos sociais e ambientais na estratégia, na operação do negócio. Reforçando o conceito do triple bottom line (TBL, os três P: Profit, People, Planet), proposto por John Elkington. John Elkington, definiu o conceito em 1998 em seu livro "Canibais com Garfo e Faca".

$\mathrm{O}$ conceito do TBL refere-se basicamente à prosperidade econômica, qualidade ambiental e progresso social, além da construção de métricas que permitam mensurar a atuação de uma empresa nas esferas econômica, social e ambiental. 
É sabido, que as práticas corporativas não estão seguindo de fato, a definição do conceito de desenvolvimento sustentável, muito menos respeitando o TBL, o tripé da sustentabilidade. Os objetivos das empresas, em sua maioria ainda são de caráter financeiro, a sustentabilidade está refletida na solidez e nos lucros auferidos. O que nos permite vê-los como um paradoxo. Onde, "as empresas são obrigadas a se projetar no futuro, e por isso não podem ignorar as questóes de desenvolvimento sustentável" (PERRET, 2011, p. 58).

Um argumento para a participação do setor privado para a transição de um modelo sustentável é apresentado por Abramovay (2012). Ele argumenta que os negócios privados estão expostos a diversas formas de julgamento público e respondem "a um conjunto mais ou menos difuso de pressóes que ampliam os riscos empresariais e obrigam as companhias a transformar os vinculos com base nos quais realizam os seus negócios" (ABRAMOVAY, 2012, p. 130). Assim, é necessário entender os mercados além da sua função de determinação de preços.

Diante da necessidade de transparência e a cobrança para uma economia que promova desenvolvimento sustentável, é cada vez maior a cobrança para que empresas apresentem relatórios e iniciativas segundo a lógica do triple bottom line. Demanda-se que a busca pelo lucro deve respeitar uma responsabilidade ética em relação às pessoas e ao meio ambiente.

Para promoção do desenvolvimento sustentável, é necessário ir além. É necessário alterar a forma de fazer negócios, de produzir e de tratar as pessoas.

A coisa toda é complexa. Nem sempre lucrativa. E as companhias precisam inaugurar o placar e passar efetivamente a fazer algo (ABRAMOVAY, 2012, p. 132). É necessário modificar as economias dos países para avançar rumo ao desenvolvimento sustentável, é necessário implementar os princípios da sustentabilidade no desenvolvimento econômico (UNEP (Programa das Nações Unidas para o Meio Ambiente, 2012).

Observamos que a maioria das corporações criou um departamento de sustentabilidade, com a função de criar imagem de empresa sustentável e ao mesmo tempo desenvolver atividades relacionadas ao tema.

Podemos dizer que, ainda existe a proliferação de um marketing socioambiental, que surge com a expressão Green was hing referindo-se a atitudes enganadoras, conhecidas como "marketing verde". Este é o caso de empresas que criaram uma imagem de instituição sustentável a partir de atividades socioambientais, a fim de lucrar com a venda de produtos e/ou serviços que causam danos ao meio ambiente e a sociedade. Mas, a transição para uma economia capaz de promover desenvolvimento sustentável 
é uma tendência da economia mundial. Seus propulsores tendem a ser regulatórios. Entendemos por propulsores aqueles que exerçam poderes ou funções na criação e acompanhamento de legislação, na função de aplicar multas e/ou correções, na função de fomentar e cobrar mudanças e posicionamentos. Podemos mencionar: o Banco Central, o Ministério Público, a Defensoria Pública, a União, os Estados-membros, os Municípios, o Distrito Federal, as autarquias, entre outros.

A sustentabilidade está cada vez mais sendo considerada uma propriedade nas agendas corporativas e tornando-se mais mainstream. (ROBECOSAM, 2017, p. 34). Nos últimos anos, investidores, consumidores, a sociedade em geral, têm prestado mais atenção aos impactos socioambientais do setor privado. Surgindo a necessidade de integrar a sustentabilidade aos valores das empresas. Um dos principais temas que surgiram entre os investidores institucionais nos últimos anos é a necessidade de se afastar da mentalidade de curto prazo e redirecionar as estratégias corporativas e de investimento rumo à geração de valor em longo prazo. (ROBECOSAM, 2017, p. 5).

De acordo com a Robeco SAM, é importante avaliar as práticas de sustentabilidade corporativa, passando a mensagem de que os investidores esperam que as empresas tenham foco nos drivers de valor de longo prazo, em vez de lucros no curto prazo. (ROBECOSAM, 2017, p. 5).

Ao passo que, um número progressivo de investidores espera medir e gerenciar os impactos socioambientais associados às suas carteiras de investimentos, eles demandam dados quantitativos sobre sustentabilidade que sejam comparáveis, financeiramente relevantes e alinhados aos negócios. Evidenciando a relevância dos índices de sustentabilidade empresarial, associados às principais Bolsas de Valores. Uma vez que retiram a sustentabilidade do discurso ou do greenwhasing e a colocam no centro, na estratégia de negócios. Exigindo das empresas, uma estratégia de negócios capaz de gerar valor ao longo prazo e promover desenvolvimento, considerando aspectos sociais, ambientais e econômicos. Fortalecendo o tripé da sustentabilidade.

\section{SUSTENTABILIDADE: ATIVO INTANGÍVEL E GERAÇÃO DE VALOR DE LONGO PRAZO}

Para muitas empresas, a marca e a cultura empresarial são seus maiores patrimônios. Nesse sentindo chamamos a atenção para o conceito de ativo intangível, intangível é algo que não podemos calcular ou tocar. Como por exemplo o valor da marca ou a cultura empresarial no longo prazo. 
Valores intangíveis podem se transformar facilmente em vantagens competitivas. O conceito de ativo intangível, a partir da teoria contábil, é fundamentado na concepção econômica de um elemento de inexistência corpórea que proporciona benefício econômico futuro à empresa. (SCHMIDT \& SANTOS, 2009, p. 4).

Assim, uma empresa ao adotar valores intangíveis de sustentabilidade tem potencial para aumentar o seu valor de mercado. Reforçando que o valor intangível, a sustentabilidade, passa a ser o bem mais valioso dessa empresa. Logo, a preocupação com as pessoas, com o meio ambiente e com o desenvolvimento econômico, potenciará a lucratividade e a geração de valor de longo prazo.

A Sustentabilidade Corporativa passou a ser mais que um conceito importante. De fato, passou a ser um vetor determinante no sucesso das empresas, seja por estimular sua capacidade de interagir com seus stakeholders gerando ganhos para ambas as partes, seja por sua preponderância de construção de reputação e credibilidade a partir de questões como transparência, ética, cidadania corporativa e responsabilidade social empresarial. (STRATEGY PARTNERS, 2011, p. 6).

A forma como a empresa se relaciona com os seus públicos deve refletir esses valores, reforçando uma postura ética e sendo questionada e medida sistematicamente, uma vez que todos esses stakeholders (ou seja, sua cadeia de valor e interesses) são também corresponsáveis pela promoção do desenvolvimento sustentável.

Diante dessa corresponsabilidade, a sociedade, na figura de suas ONGs, dos órgãos governamentais, da imprensa e na própria figura do indivíduo-cidadão (como eleitor, consumidor e acionista/investidor) passa a exigir das empresas, principalmente as de capital aberto, que estas adotem a prática da transparência no seu processo de governança corporativa e distribuição de riqueza, obrigando-as a mostrar, a quem de direito, que estão devolvendo à sociedade os recursos que utilizam para produzir suas riquezas. Mais que intenção, sustentabilidade triple bottom line é resultado aparente e transparente. (STRATEGY PARTNERS, 2011, p. 6).

Pensar em lucro é premissa de existência de uma empresa; mas não finalidade absoluta. Os consumidores estão cada vez mais cientes do seu poder de transformação social e começam a demandar mais responsabilidade das empresas. Para jogar o jogo de hoje, é preciso pensar além dos ganhos empresariais, é preciso avaliar o que a comunidade, a região, o país e mesmo o mundo vão ganhar com o sucesso da empresa. (Ibidem). 
Logo, como agente econômico, a capacidade de gerar riqueza que de uma empresa, torna-se dependente de aprovação social, considerando os seus processos de satisfação.

A postura de empresa tri-sustentável reconhecida pela sociedade (e consumidores) passa a ser tão importante quanto a excelência e o sucesso em sua atividade fim, o que configura Sustentabilidade Corporativa como um ativo intangível fundamental da empresa, uma vez que é ativo, por ter seu valor reconhecido, mas é intangível, por ser de difícil qualificação e de quantificação ainda impraticável (ou, no melhor dos cenários, ainda carente de modelos formais homologados para a prática gerencial-contábil). (Ibidem).

Nesse sentido, reforçamos que a imagem da empresa é "quase" tudo o que ela tem no mercado. Reputação, nos dias atuais está totalmente alinhada à sustentabilidade, ou seja, a forma como a empresa está se relacionando com às questôes social, ambiental e econômica. Uma marca, símbolo da organização, bem cuidada ao longo dos anos vale mais do que qualquer ganho de curto prazo.

A lógica de mercado Investidores já descobriram isto, ações de empresas com reputação em sustentabilidade tem alcançado valorização superior em até $12 \% \mathrm{em}$ relação às ações de empresas sem este valor intangível. (ROBECOSAM, 2017). Esse dado é avaliado a partir da comparação da evolução histórica do valor das ações de empresas listadas nos índices DS 400 - Dow Jones Sustainability (Sustentáveis) e S\&P 500 (Convencionais).

Também, de acordo com a pesquisa do Ibmec-SP em 2008, constatou que empresas listadas no ISE (Índice de Sustentabilidade Empresarial da BMF-Bovespa), possuíam ativos intangíveis fortes, apresentando valores de mercado até 19\% superiores em comparação com aquelas empresas que não estavam listadas. Fatos que contraria a afirmação de Friedman, onde as empresas devem apenas se preocupar com os lucros.

Friedman (1970) ressalta que a única responsabilidade social da empresa é a de gerar lucros e riquezas para os seus acionistas, tendo como responsabilidade o desempenho econômico, onde qualquer posição diferente dessa poderá enfraquecer as empresas e o sistema capitalista. Por outro lado, é possível gerar lucros se os recursos naturais e as questões sociais forem agravadas?

O envolvimento da empresa em ações socioambientais gera gastos desnecessários, resultando em custos adicionais e desvantagem competitiva. (Friedman, 1970). 
Contrariando os argumentos de Friedman, a Sustentabilidade evoluiu nos últimos anos, gerando valor às empresas e tornando-se vantagem competitiva. Nesse sentido, torna-se impossível que o empresário foque apenas no lucro.

A pressão dos stakeholders à necessidade de as empresas inserirem a sustentabilidade nas formas de fazer negócios e gerar valor demandam novas responsabilidades por parte das empresas. A procura por investimentos socialmente responsáveis tem determinado a criação de indicadores, para identificar as empresas que de fato estão incorporando novas responsabilidades.

Os impactos das alterações climáticas, os entraves ao desenvolvimento econômico e as dificuldades sociais, são questôes que precisam estar presentes nos desafios e resultados das empresas. Pois são questóes essenciais para a continuidade dos negócios. Dessa forma, investidores e gestores de carteiras passaram a buscar informações objetivas e transparentes sobre a sustentabilidade corporativa, para tomar decisões de alocação e oportunidades de mercado, engajando em causas relevantes que afetarão suas taxas de retorno e obrigações fiduciárias no futuro. (BLOOMBERG, 2016 - p. 1).

É notório que, no longo prazo, não será possível fazer negócios, sem atentar a sustentabilidade. "A medida que os investidores ficam mais envolvidos, aumenta o foco na qualidade e relevância dos dados e diminui o foco na quantidade". (Ibidem, p. 2). A sustentabilidade tem que estar inserida no core business das empresas (estratégia central). $\mathrm{O}$ discurso não pode ser mais isolado da prática.

A Sustentabilidade Corporativa passa a ser considerada uma abordagem de negócios, com capacidade de gerar valor de longo prazo para o acionista, ao abraçar oportunidades e gerenciar riscos decorrentes dos seus impactos econômicos, ambientais e sociais. - Ressaltamos assim que, as práticas de negócios sustentáveis são fundamentais para a criação de valor de acionista de longo prazo em um mundo cada vez mais limitado de recursos. Além disso, os fatores de sustentabilidade representam oportunidades e riscos que as empresas competitivas devem se atentar.

\section{PRINCIPAIS ÍNDICES E INDICADORES DE SUSTENTABILIDADE CORPORATIVA}

As empresas vêm redescobrindo indicadores tradicionais no campo da economia e das finanças, porém formulados de maneira bastante moderna e sofisticada, disseminando seu uso de forma globalizada (ASSAF NETO, 2002, p. 206). 
A análise financeira das empresas sempre esteve relacionada à solidez e performance. Dessa forma, com a evolução do conceito de sustentabilidade, tornou-se necessário a criação de indicadores (índices), que permitissem o acompanhamento e a medição do nível de engajamento das empresas com a sustentabilidade. Uma forma de verificar, se de fato, a sustentabilidade não estava apenas no discurso do setor privado.

Os indicadores tornaram-se muito relevantes, demandando a necessidade de mudanças por parte das empresas. Além disso, o agravamento das questóes ambientais, econômicas e sociais em escala mundial, a pressão por parte dos consumidores e da sociedade em geral, às práticas sustentáveis, demandam que as empresas, de fato, demonstrem a sua performance em relação a Sustentabilidade, reforçando que estão contribuindo com o Desenvolvimento Sustentável. (BM\&F Bovespa, 2012, p. 4).

Para os investidores, a sustentabilidade representa uma oportunidade, na medida em que o mercado de Investimentos Sustentável segue a sua trajetória de expansão e comprova a demanda por empresas com atividades capazes de se sustentar no longo prazo.

Nesse sentido, destacamos os principais índices de sustentabilidade, que possuem abordagens relevantes para medir a maturidade da sustentabilidade dentro das corporações:

\section{ISE - Índice de Sustentabilidade Empresarial ${ }^{5}$}

O ISE foi uma iniciativa pioneira na América lática, lançado com o objetivo de criar um ambiente de investimento compatível com as demandas de desenvolvimento sustentável da sociedade contemporânea, estimulando e verificando a responsabilidade ética das corporações.

5 Iniciado em 2005, financiado pela International Finance Corporation (IFC), braço financeiro do Banco Mundial, com a metodologia de responsabilidade do Centro de Estudos em Sustentabilidade (GVCes) da Escola de Administração de Empresas de São Paulo da Fundação Getúlio Vargas (FGV-EAESP). A Bolsa é responsável pelo cálculo e pela gestão técnica do índice. (BM\&F Bovespa, 2017). Jones Sustainability Index. Dessas, 867 de 42 países conseguiram submeter. Sendo, apenas 470 empresas de 32 países qualificadas para o índice. (ROBECOSAM, 2017, p. 36). Observa-se, que as empresas começam a compreender a importância de realmente medir o valor dos seus impactos, objetivando o valor de longo prazo. Nesse sentido, a avalição dos riscos ambientais, sociais e de governança corporativa, visando as oportunidades de forma estratégica, demonstra como a sustentabilidade está inserida nas corporações ao gerarem negócios. Conhecer a estratégia da empresa é essencial para entender/ encontrar os drivers de sustentabilidade. Ou seja, entender qual a estratégia da empresa e se de fato ela está preocupada com a sustentabilidade. Se elas estão colocando a sustentabilidade no core business e buscando a geração de valor no longo prazo. 
O ISE é considerado um indicador de desempenho médio das cotações dos ativos de empresas com reconhecido comprometimento com a sustentabilidade empresarial (BM\&F Bovespa, 2017). Trata-se de uma ferramenta para análise comparativa do desempenho, de algumas empresas listadas na bolsa de valores sob o aspecto da sustentabilidade corporativa, baseada em eficiência econômica, equilíbrio ambiental, justiça social e governança corporativa (ibidem, ibidem2017).

Com a criação do ISE, a Bovespa permitiu a ampliação do entendimento sobre empresas comprometidas com a sustentabilidade. A avaliação é realizada a partir de um questionário, composto por 7 dimensões: Geral, Natureza do Produto, Governança Corporativa, Econômico-Financeira, Ambiental e Social.

No ciclo 2016/2017, 179 empresas foram convidadas a participar da carteira, sendo elegíveis 34. A carteira atual, também contou com a exclusão de 2 empresas. (BM\&F Bovespa, 2017).

\section{DJSI - Dow Jones Sustainability Index World}

Índice lançado em 1999, como o primeiro indicador da performance financeira das empresas líderes em sustentabilidade a nível global. O monitoramento do indicador é realizado pela RobecoSAM, empresa suíça que coordena o Índice, através de um questionário composto por três (3) dimensões: Econômica, Social e Ambiental. Além das dimensões do questionário a ROBECOSAM avalia a exposição das empresas em mídias públicas. Do ponto de vista da transparência de informações e/ou envolvimentos em questôes polêmicas que podem apontar riscos reputacionais ou danos socioambientais para a sociedade. (ROBECOSAM, 2017).

A Avaliação de Sustentabilidade Corporativa (CSA) da RobecoSAM tornou-se uma das avaliações de sustentabilidade corporativa mais antigas do mundo. (ROBECOSAM, 2017, p. 9). A cada ano um número crescente de empresas demonstram o seu compromisso com a sustentabilidade, participando ativamente da Avaliação de Sustentabilidade Corporativa. As respostas das empresas ao DJSI permitem entender como os seus negócios afetam ou podem afetar o nosso planeta e a sociedade em geral. (ROBECOSAM, 2017, p. 6).

De acordo, com a ROBECOSAM, em 2016, 3.420 empresas em todo mundo foram convidadas a participar do CSA (Corporate Sustainability Assessment), questionário do Dow. 


\section{CONCLUSÃO}

Pensar a sustentabilidade, a partir do conceito desenvolvido pela ONU, sustentando a preocupação de satisfazer as necessidades do presente sem comprometer a possibilidade das geraçôes futuras de satisfazerem suas próprias necessidades, tornou-se desafiador e demandou um comprometimento e uma mudança na atuação do setor privado. Reforçando a necessidade de pensar nas questôes sociais, ambientais e econômicas. Mantendo o tripé da sustentabilidade.

A partir das contribuições de Amartya Sen, percebemos que o conceito de necessidades, alinhado ao conceito inicial de sustentabilidade, também evoluiu, ultrapassando a barreira de renda como sinônimo de pobreza.

As megatendências relacionadas à sustentabilidade estão inquietando a sociedade e os investidores em geral. É preciso, por parte das empresas, apresentar um impacto mensurável. É preciso comprovar as ações sustentáveis.

Os desafios a longo prazo, ora na dimensão ambiental, como a escassez de recursos e as alterações climáticas. Ora na dimensão social, como o aumento da pobreza, a ausência de serviços como educação e saúde. Ora na dimensão econômica, como negócios que prejudicam a sociedade, corrupção por parte das empresas, estão a redefinir as expectativas da sociedade em relação à atuação empresarial. Ampliando o senso de urgência e cobranças por atitudes positivas. Nesse sentido, tais desafios criam novas oportunidades e novos riscos que as empresas devem enfrentar hoje para permanecerem competitivas amanhã. Pensar no longo prazo é essencial.

As empresas que antecipam e gerenciam as oportunidades e os riscos econômicos, ambientais e sociais atuais e futuros, com foco na qualidade, inovação e produtividade, emergirão como líderes e terão maior probabilidade de criar uma vantagem competitiva e gerar valor de longo prazo para a sociedade e para os investidores.

Inserir a sustentabilidade na estratégia empresarial e repensar a forma de atuação, excluindo o pensamento egocêntrico da lucratividade pura, torna-se urgente e vital para o setor privado.

A Sustentabilidade saiu da esfera do simples conceito, do greenwashing. E, passou a assumir posição de destaque na geração de valor, tornando-se ativo "intangível" e relevante para as empresas.

\section{REFER̂̂ECIAS}

ABROMOVAY, Ricardo. Muito além da economia verde. São Paulo: Abril, 2012.

ASSAF NETO, A. Estrutura e análise de balanço. 7. ed. São Paulo: Atlas, 2002. 
BLOOMBERG - 2016: Critérios de Sustentabilidade entram objetivamente nas decisões de investimento. Bloomberg Brasil Blog - 23 de março de 2016. Disponível em: https:// www.bloomberg.com.br/blog/criterios-de-sustentabilidade-entram-objetivamente-nasdecisoes-de-investimento/.

BM\&F Bovespa - http://www.bmfbovespa.com.br/pt_br/produtos/indices/indices-desustentabilidade/indice-de-sustentabilidade-empresarial-ise.htm - Pesquisa o valor do ISE - 2012.

http://www.bmfbovespa.com.br/pt_br/produtos/indices/indices-de-sustentabilidade/indice-de-sustentabilidade-empresarial-ise.htm. 2017.

CAMPOS, Carlos da Silva. Relatório de Brundtland: a versão original, 1987. Ambiente, 22 mar. 2011. Disponível em: <https://ambiente.wordpress.com/2011/03/22/relatriobrundtland-a-verso-original/>. Acesso em: 29 set. 2016.

CDES - Conselho de Desenvolvimento Econômico e Social. Documento de contribuição brasileira à Conferência Rio + 20. Brasília, nov. 2011. Disponível em:<http://www. radarrio20.org.br/arquivos/files/rio20_propostabr_182.pdf>. Acesso em: 7 nov. 2016.

FGV \& FEBRABAN. O Sistema financeiro nacional e a economia verde: alinhamento ao desenvolvimento sustentável. São Paulo: Febraban, 2014. Disponível em: <http://mediadrawer. gvces.com.br/publicacoes/original/sistemafinanceironacionaleconomiaverde_febrabangvces_abril2015.PDF>. Acesso em: 10 nov. 2016.

FRIEDMAN, Milton. The social responsibility of business is to increase its profits. New York Times Magazine. New York, n. 33, p. 122 - 126, set. 1970.

PERRET, Bernard. O capitalismo é sustentável? São Paulo: Loyola, 2011.

ROBECOSAM - 2017 - The_Sustainablity_Yearbook_2017_em_portugues: Disponível em: http://yearbook.robecosam.com/fileadmin/Files/Documents/Portuguese/The_ Sustainablity_Yearbook_2017_em_portugues.pdf.

SCHMIDT, Paulo; SANTOS, José Luiz dos. Avaliação de ativos intangíveis. 2. ed. São Paulo: Atlas, 2009.

SEN, Amartya. 1999. Sobre ética e economia. São Paulo: Companhia das Letras. . 2000. Desenvolvimento como liberdade. São Paulo: Companhia das Letras.

STRATEGY PARTNERS - O que são Ativos Intangíveis e como geram Valor às Empresas, 20 de setembro de 2011. Disponível em: http://dom-ecc.com.br/o-que-sao-ativosintangiveis-e-como-geram-valor-as-empresas/. Acessado em 23/04/2017.

UNITED Nations Environment Programme. Towards a green economy: pathways to sustainable development and poverty eradication. S. 1.: Unep, 2011.

WORLD Bank. World development indicators on line. 2014. Disponível em: http://data. wolrdbank.org/data-catalog/world-development-indicators>. Acesso em: 17 out. 2016.

WORLD Commission on Environment and Development. Our common future. Oxford: Oxford University Press, 1987. 